\title{
МОНИТОРИНГ ТЕХНОГЕННОГО ЗАСОРЕНИЯ КОСМИЧЕСКОГО ПРОСТРАНСТВА. ПРОБЛЕМЫ И РЕШЕНИЯ
}

\section{SPACE DEBRIS MONITORING. PROBLEMS AND SOLUTIONS}

\begin{abstract}
Ю.Н.Макаров, д.э.н., директор департамента стратегического планирования и организации космической деятельности Государственной корпорации по космической деятельности "Poскосмос" / Makarov.YN@roscosmos.ru Yu.N.Makarov, Doctor of Economics, Director of the Department of Strategic Planning and Organization of Space Activities of the State Space Corporation Roscosmos
\end{abstract}

DOI: 10.22184/1993-8578.2019.12.1.6.14

\begin{abstract}
Аналитический обзор современной проблематики мониторинга засорения околоземного космического пространства составлен по материалам официальных докладов автора на Восточном экономическом форуме (г. Владивосток) в 2016 и 2017 годах, на заседаниях Президиума РАН 15 января 2019 года и Совета РАН по космосу 11 мая 2018 года (г. Москва) по различным аспектам устойчивого развития космической деятельности: снижению техногенного засорения космического пространства, мониторингу природной и техногенной обстановки в околоземном космическом пространстве (ОКП), противодействию космическим угрозам, в том числе связанным с техногенным засорением космического пространства.

The analytical review of the problems of space debris monitoring of near-Earth space was based on the author's speeches at the Eastern Economic Forum (Vladivostok) in 2016 and 2017, at meetings of the Presidium of the Russian Academy of Sciences on January 15, 2019 and the Council of the Russian Academy of Sciences on Space May 11, 2018 ( Moscow) on various aspects of the sustainable development of space activities: preventing and minimization the creating space debris, monitoring the natural and technogenic situation in the space, threats counteraction, including the ones associated with the space pollution.
\end{abstract}

Комплексный характер проблемы противодействия космическим угрозам, связанным с техногенным засорением космического пространства, высокая степень научно-технической сложности ее решения, а также значительная ресурсоемкость мероприятий, подлежащих реализации в периметре решаемых задач объективно обусловливают необходимость тесного межведомственного взаимодействия заинтересованных ведомств и организаций при обеспечении общей координации работ на государственном уровне.

Находящаяся в сфере ответственности Госкорпорации "Роскосмос" проблема техногенной засоренности околоземного космического простран ${ }^{-}$ ства в последние годы активно обсуждается. Ее возникновение является побочным эффектом, негативным результатом более чем 60-летней космической деятельности.

За этот период активного освоения околоземного космического пространства на орбитах произошло более 250 разрушений техногенных космических объектов вследствие взрывов и столкновений. В космосе остались тысячи отработавших космических аппаратов и ступеней ракет-носителей, а также различных технологических фрагментов. В результате количество находящихся на орбите объектов так называемого космического мусора, размер которых превышает 1 см в поперечнике, составляет по разным оценкам от 600 до 700 тыс.

Ситуация усугубляется резко возросшей в последние годы интенсивностью космической деятельности, значительным увеличением участников этой деятельности, которые зачастую не координируют свои действия в космосе. Тем самым, не только космический мусор, но и функционирующие космические аппараты могут создавать угрозу другим функционирующим космическим аппаратам. В настоящее время в околоземном пространстве находится немногим более 2 тыс. функционирующих космических аппаратов 


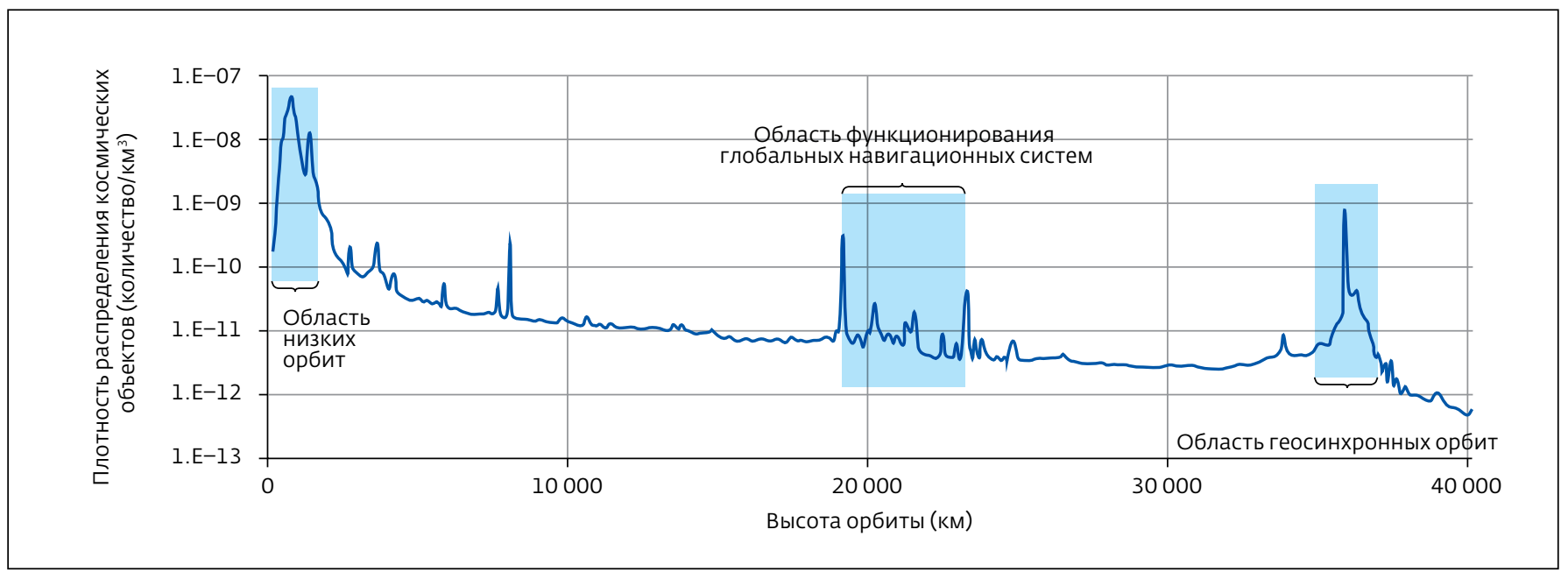

Puс.1. Распределение массы космического мусора по основным освоенным орбитальным областям

Fig.1. Distribution of the mass of space debris in the main developed orbital regions. Sourse: 54th Session of the STCS, COPOUS, UNO, NASA, 2017

(КА). В ближайшие годы прогнозируется взрывной рост числа КА за счет развертывания так называемых сверхбольших спутниковых систем, каждая из которых может включать до нескольких тысяч космических аппаратов.

Распределение объектов космического мусора по орбитальным областям неравномерно (см. рис.1). Так, до 99\% функционирующих КА размещается в трех основных областях околоземного пространства - это область низких орбит высотой до 1500 км, область геостационарной орбиты (единственной в своем роде) и область средневысоких орбит высотой 19-21 тыс. км. Соответственно, в этих же областях концентрируется и наибольшая масса космического мусора.

Финансовые вложения в создание, запуск и эксплуатацию космических аппаратов огромны. К примеру, общая стоимость космических аппаратов, функционирующих в настоящее время в области геостационарной орбиты, превышает 100 млрд долл. Учитывая это обстоятельство, а также то, что использование космоса позволяет решать разнообразные прикладные задачи с целью реального повышения уровня жизни населения, проблема космического мусора переходит из категории теоретических в категорию сугубо насущных, требующих решения.

Необходимы достоверные количественные оценки, характеризующие потенциальную опасность объектов космического мусора, позволяющие оценивать реальные угрозы, возникающие для конкретных космических аппаратов. Для получения таких оценок необходимо наличие полной, достоверной, точной и оперативной информации о реальной ситуации в околоземном космосе. Кроме того, эффективное реагирование на такие угрозы невозможно без развитых механизмов обработки и анализа информации мониторинга объектов космического мусора с целью предоставления полученных результатов конечным потребителям.

Информация о текущей обстановке в околоземном космическом пространстве складывается из данных о следующих основных элементах:

- объектах искусственного происхождения (техногенных объектах), которые включают и функционирующие КА, и всевозможные объекты космического мусора;

- событиях (операциях) в околоземном космосе, вносящих изменения в количественный и качественный состав объектов;

- радиоэлектронной обстановке, которая формируется совокупностью излучений бортовых передатчиков КА и наземных станций управления;

- факторах естественной среды, которые по своей сути представляют опасность для функционирования автоматических и пилотируемых космических аппаратов.

Первые две группы элементов непосредственно затрагивают проблему космического мусора.

В 2010 году Госкорпорацией "Роскосмос" (в то время - Федеральным космическим агентством) было принято решение о создании специализированной системы, которая обеспечивала бы безопасность проведения операций в космосе в условиях его техногенной засоренности и резкого повышения интенсивности использования большим количеством участников, не имеющих средств и потребности во взаимной координации деятельности в космосе. 


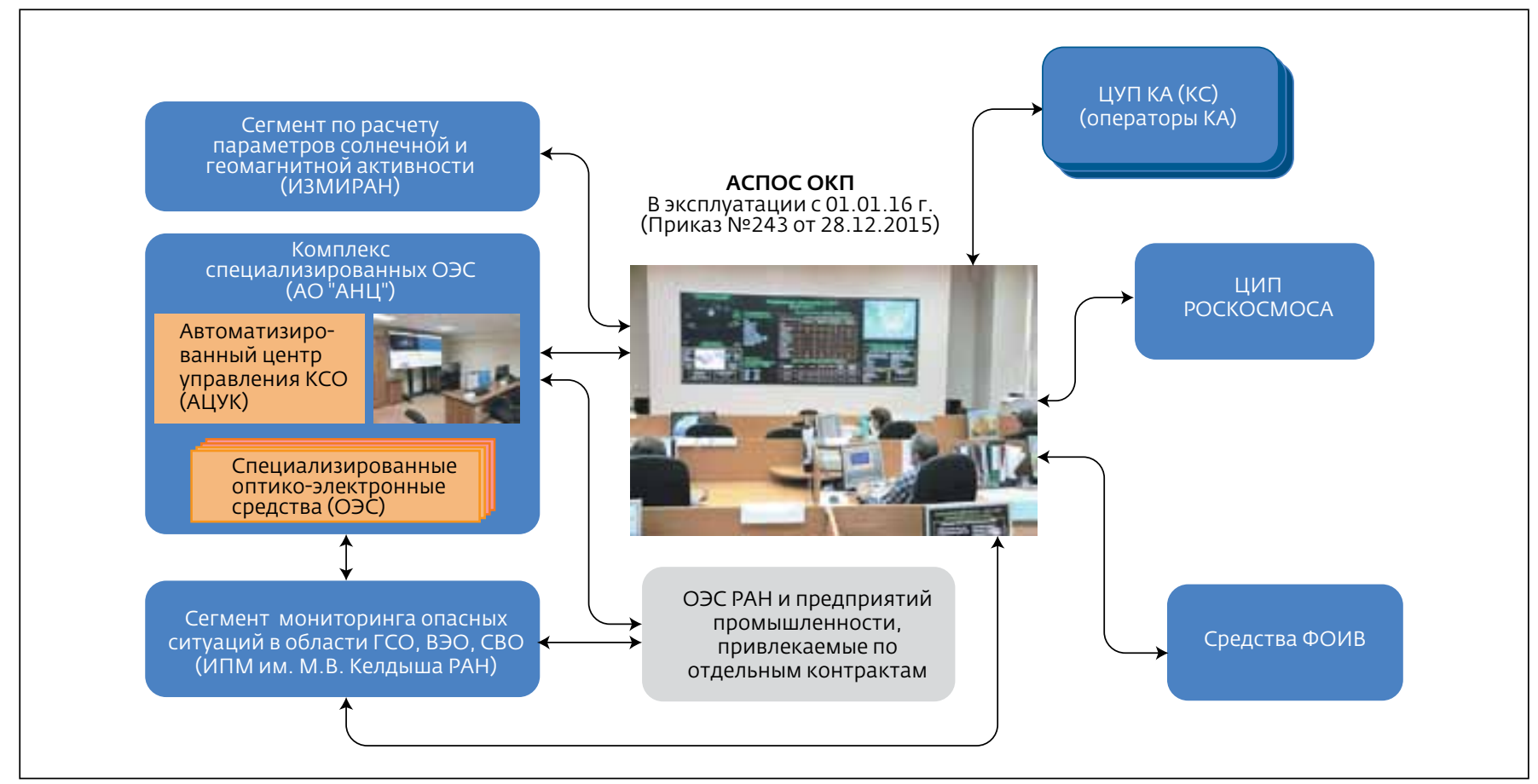

Рис. 2. Действующая структура АСПОС ОКП и функциональные связи с внешними абонентами Fig.2. The structure of the Automated Warning System for Hazardous Situations in Outer Space (ASPOS OKP)

Такая система - "Автоматизированная система предупреждения об опасных ситуациях в околоземном космическом пространстве" (АСПОС ОКП) создана в рамках Федеральной космической программы России.

Госкорпорация "Роскосмос" с 1 января 2016 года осуществляет штатную эксплуатацию АСПОС ОКП, которая призвана решать следующие задачи:

- автоматизированный сбор, обработку и анализ информации об объектах и событиях в ОКП, получаемой с использованием комплекса специализированных оптико-электронных средств (КСОЭС);

- выявление, траекторное сопровождение, оценку свойств и постоянный мониторинг объектов и событий в ОКП, которые могут представлять потенциальную угрозу для российских КА гражданского и двойного назначения.

К ним относятся: сближения с другими космическими объектами (как функционирующими, так и не функционирующими), создающими угрозу физического столкновения; разрушения космических объектов на орбите; объекты, которые могут быть источником вредных радиочастотных помех; объектов, о фактическом положении которых в ОКП нет информации в каких-либо иных источниках;
- сопровождение выведения на целевые орбиты КА, запускаемых в рамках Федеральной космической программы России (в том числе в нерасчетных и аварийных случаях);

- контроль мероприятий по уводу отработавших отечественных КА, верхних ступеней ракет-носителей (РН) и разгонных блоков (РБ) в зоны "захоронения" или на орбиты, на которых объекты имеют ограниченный срок баллистического существования;

- контроль выполнения зарубежными участниками космической деятельности рекомендаций по снижению засоренности ОКП;

- прогнозирование неуправляемых сходов с орбит и падений космических объектов (КО) риска (объектов, имеющих значительную массу или содержащих на борту опасные вещества) с определением времени и возможного района падения;

- доведение получаемой информации до ЦУП космических аппаратов, руководства Госкорпорации "Роскосмос", других потребителей.

Кроме того, система играет важную роль в информационном обеспечении в процессе выполнения международных обязательств Российской Федерации по проблеме космического мусора.

В состав системы входят:

- главный информационно-аналитический центр (ГИАЦ), расположенный в г. Королеве; 


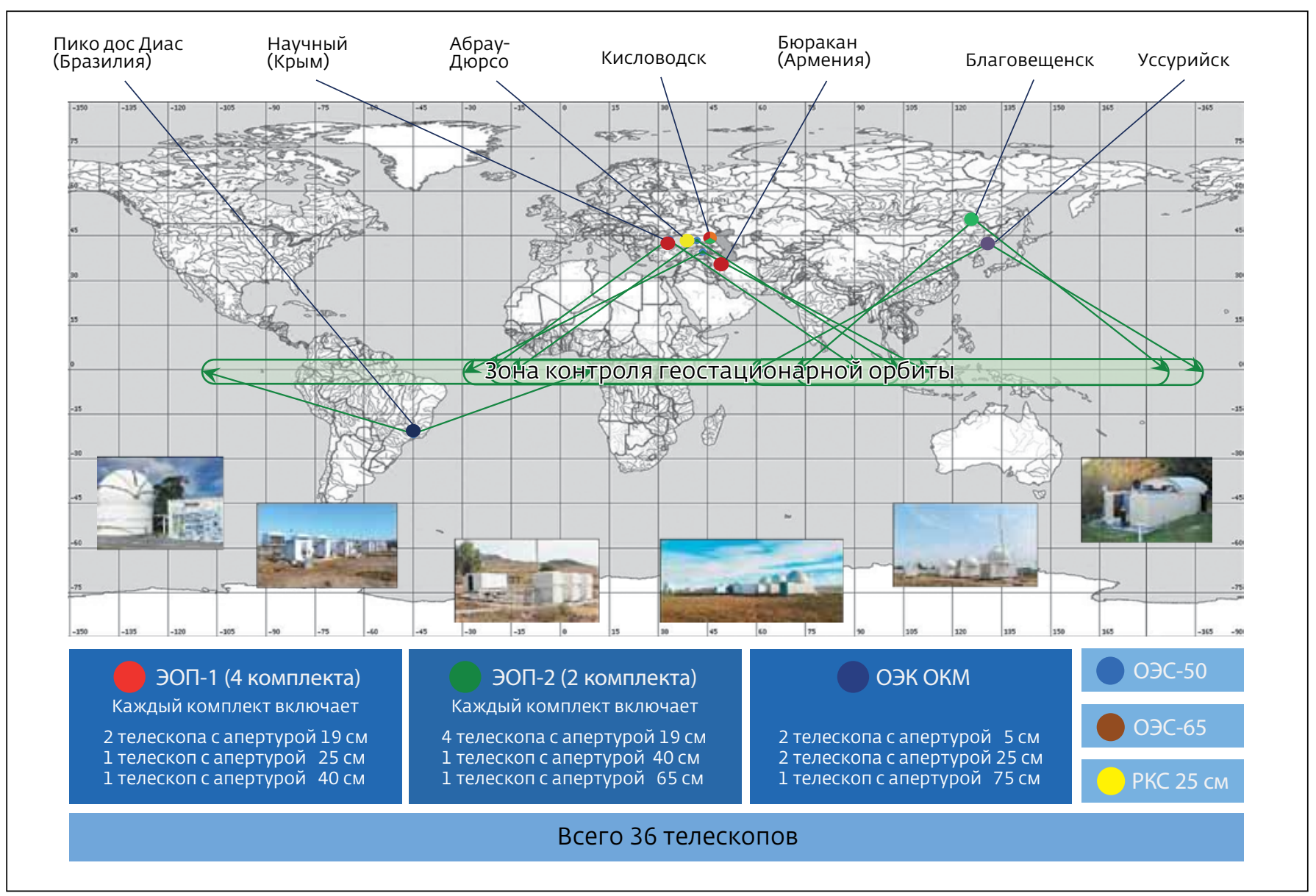

Рис.3. Дислокация измерительных средств АСПОС ОКП и зона контроля геостационарной орбиты Fig.3. Operational optical facilities of ASPOS OKP

- сегмент мониторинга опасных ситуаций в области геостационарных (ГСО), высокоэллиптических (ВЭО) и средневысоких околокруговых (СВО) орбит, расположенный в г. Москве;

- сегмент по расчету параметров солнечной и геомагнитной активности, расположенный в г. Троицке;

- комплекс специализированных оптико-электронных средств (КСОЭС) с автоматизирован ${ }^{-}$ ным центром управления (АЦУК) в г. Москве и сетью территориально распределенных оптикоэлектронных средств, два из которых находятся за пределами Российской Федерации: один - в Армении и второй - в Бразилии.

Эксплуатация АСПОС ОКП осуществляется в рамках отдельного контракта по поддержанию системы в технической и эксплуатационной готовности.

Потребителями системы являются Центр управления полетами КА научного и социально-экономического назначения, Центральный информационный пункт (ЦИП) Госкорпорации "Роскосмос", а также соответствующие подразделения федеральных органов исполнительной власти.

В настоящее время оптико-электронные средства АСПОС ОКП обеспечивают мониторинг геостационарной области, за исключением участка протяженностью $60^{\circ}$ над Тихим океаном (см. рис.3). Для мониторинга этого участка используются привлекаемые средства, эксплуатируемые различными организациями РАН и промышленности.

В составе комплекса КСОЭС - 36 телескопов, которые позволяют получать измерительную информацию по объектам, расположенным на орбитах всех типов, включая низкие (высотой менее 3500 км), геостационарные, высокоэллиптические и средневысокие околокруговые (на которых размещаются глобальные навигационные спутниковые системы).

Возможности используемых инструментов, позволяющие обнаруживать объекты размером от 25-30 см на дальности 40000 км, обеспечиваются представленным ниже составом средств. 


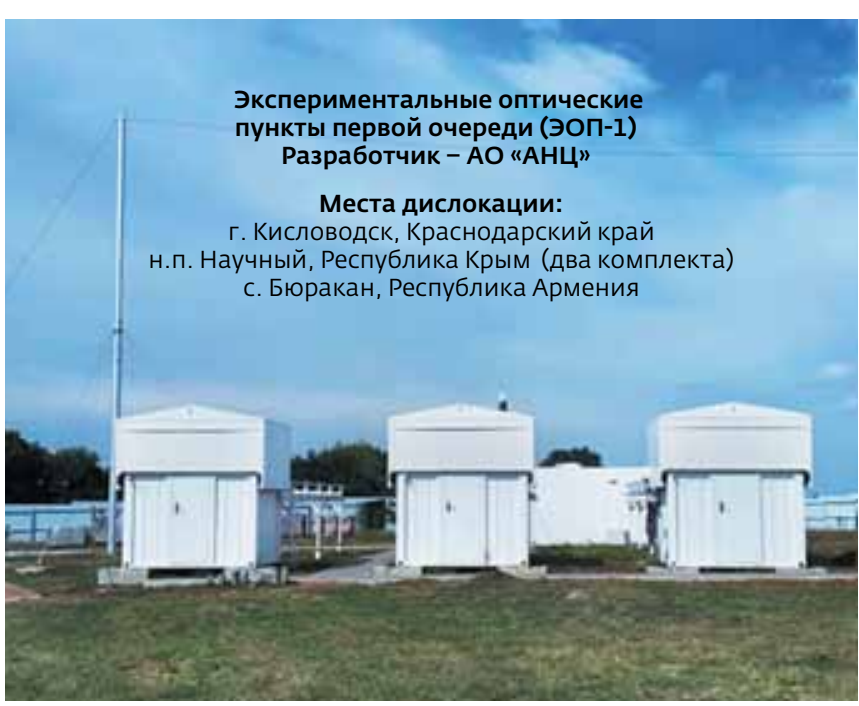

Рис.4. Комплекс специализированных оптико-электронных средств АСПОС ОКП: экспериментальные оптические пункты первой очереди (ЭОП-1)

Fig.4. The complex of specialized optical-electronic facilities of ASPOS OKP: experimental optical points of the first stage

1. Четыре экспериментальных оптико-электронных пункта первого поколения (ЭОП-1), каждый из которых включает по три инструмента: сдвоенный телескоп с широким полем зрения с апертурой каждого канала 19 см, телескоп с апертурой 25 см и телескоп с апертурой 40 см.

Сдвоенный телескоп используется для проведения наблюдений в режиме обзора, то есть многократного покрытия в течение одной ночи выбранного участка небесной сферы, например всей видимой части геостационарной области, и получения измерительной информации по всем объектам в поле зрения, в том числе и объектам новых запусков.

Этот телескоп способен за одну ночь получать до 25 тыс. измеренных положений нескольких сотен космических объектов (до 500) размером от 0,8-1 м, находящихся на высоких орбитах.

Телескопы с апертурой 25 и 40 см используются для проведения наблюдений в режиме "по целеуказаниям", то есть в режиме наведения на заданный по программе объект и получения измерительной информации по нему и по всем объектам, попутно попавшим в поле зрения.

Телескоп с апертурой 40 см способен отслеживать в геостационарной области (на дальности 37-40 тыс. км) объекты размером от 50-60 см в поперечнике.

2. Два экспериментальных оптико-электронных пункта второго поколения (ЭОП-2), каждый из которых включает по три инструмента: счетверенный

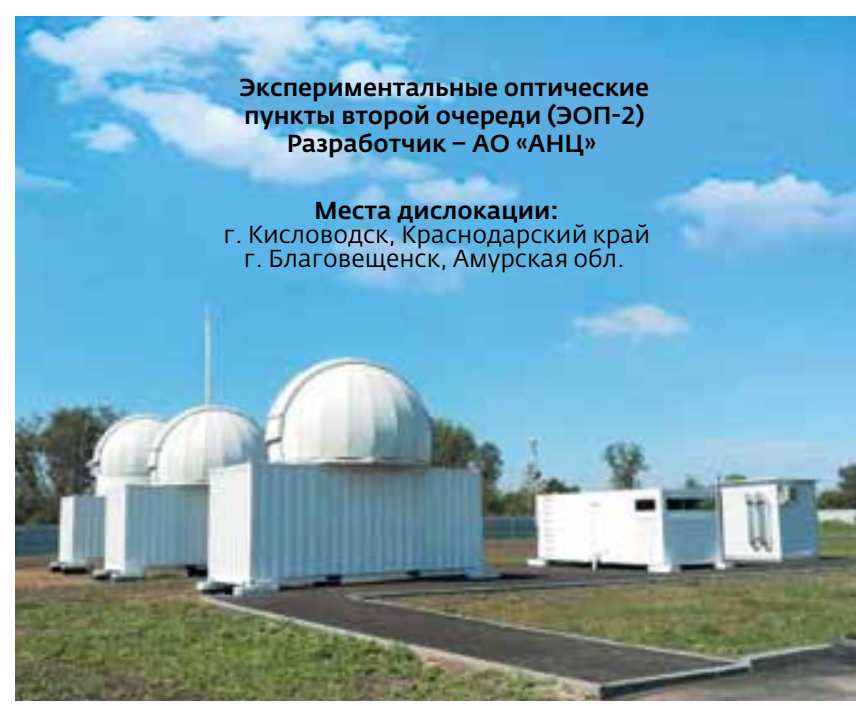

Рис.5. Комплекс специализированных оптико-электронных средств системы АСПОС ОКП: экспериментальные оптические пункты второй очереди (ЭОП-2)

Fig.5. The complex of specialized optical-electronic means of ASPOS OKP : experimental optical points of the second stage

телескоп с широким полем зрения апертурой каждого канала 19 см, телескоп с апертурой 40 см и телескоп с апертурой 65 см (рис.5).

Счетверенный телескоп используется для проведения наблюдений в режиме обзора, то есть многократного покрытия в течение одной ночи выбранного участка небесной сферы, например всей видимой части геостационарной области, и получения измерительной информации по всем объектам в поле зрения, в том числе и объектам новых запусков. Этот телескоп способен за одну ночь получать до 30 тыс. измеренных положений нескольких сотен космических объектов (до 800) размером от 0,8-1 м, находящихся на высоких орбитах.

Телескопы с апертурой 40 и 65 см используются для проведения наблюдений в режиме "по целеуказаниям", то есть в режиме наведения на заданный по программе объект и получения измерительной информации по нему и по всем объектам, попутно попавшим в поле зрения.

Телескоп с апертурой 65 см способен отслеживать в геостационарной области (на дальности 37-40 тыс. км) объекты размером от 25-30 см в поперечнике.

3. Оптико-электронный комплекс обнаружения объектов космического мусора (ОЭК ОКМ), размещенный в Бразилии, который включает три типа телескопов на одном опорно-поворотном устройстве: двухканальный телескоп с объективами со сверхшироким полем зрения и апертурой каждого канала 5 см, двухканальный телескоп 


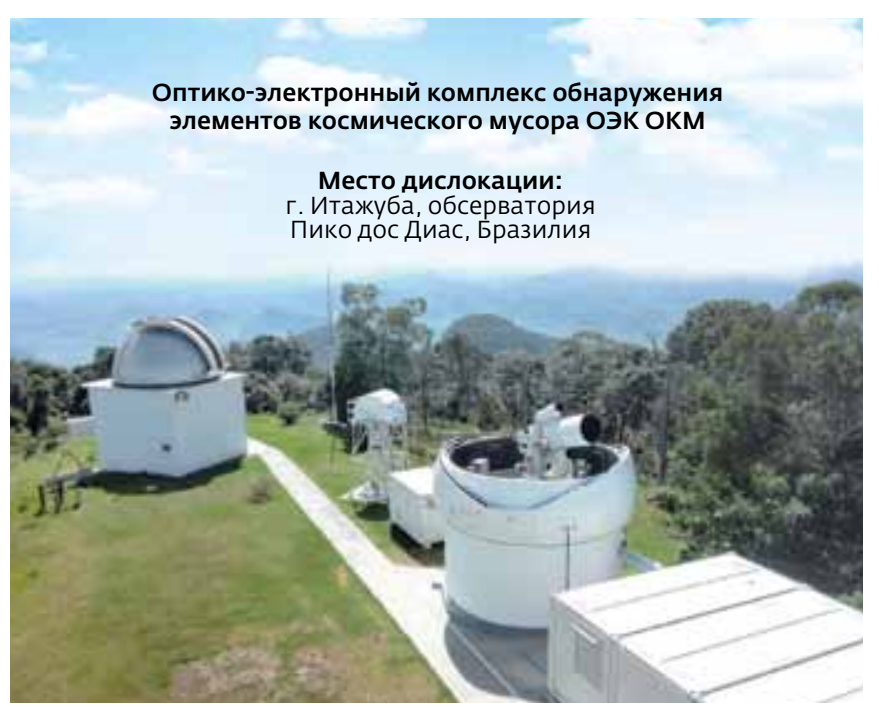

Рис.6. Комплекс специализированных оптико-электронных средств системы АСПОС ОКП: оптико-электронный компиекс обнаружения объектов космического мусора (ОЭК ОКМ) Fig.6. The complex of specialized optical-electronic means of the Automated Warning System for Hazardous Situations in NearEarth Space: optical-electronic complex for detection of space debris

с объективами с апертурой 25 см и одноканальный широкоугольный телескоп с апертурой 75 см (см. рис.6).

Объективы с апертурой 5 см используются для проведения наблюдений космических объектов на низких орбитах (высотой до 1500 км) в сумеречное время. Объективы с апертурой 25 см используются для проведения наблюдений низкоорбитальных и высокоорбитальных космических объектов в режиме обзора с высокой производительностью - до 1000 объектов за ночь. Объектив с апертурой 75 см используется для проведения обзоров видимой части геостационарной области и способен детектировать объекты размером от $30 \mathrm{~cm}$ на дальности 40 тыс. км.

Если говорить о текущих возможностях российских систем мониторинга ОКП в сравнении с аналогичными системами США, то ситуация выглядит следующим образом.

В области низких орбит основной вклад в решение задач мониторинга вносят радиолокационные средства, включая станцию, используемую в качестве радара некогерентного рассеяния для изучения ионосферы в Институте солнечно-земной физики Сибирского отделения РАН и попутно получающую измерения по низкоорбитальным объектам.

В США созданы и эксплуатируются на коммерческой основе РЛС, способные обнаруживать на низких орбитах объекты размером от 10 см. Кроме того, в ближайшее время Минобороны США планирует ввести в эксплуатацию первый пост радиолокационной станции барьерного типа, которая способна на низких орбитах обнаруживать объекты размером от 5 см. Ожидается, что количество объектов, отслеживаемых американской системой мониторинга ОКП на низких орбитах, после ввода в эксплуата цию указанной радиолокационной станции увеличится до 150-200 тыс.

В области мониторинга высоких орбит в настоящее время Россия демонстрирует лидерство по количеству сопровождаемых объектов космического мусора и по качеству решения задач сопровождения и анализа ситуации в этой важной области. Основной вклад в решение задач мониторинга высоких орбит в России вносят оптико-электронные средства системы АСПОС ОКП, оптико-электронные средства, эксплуатируемые АО "Астрономический научный центр", оптико-электронные средства институтов РАН (ИСЗФ, ИНАСАН), кооперации НСОИ АФН под руководством ИПМ им. М.В.Келдыша и предприятий промышленности.

В 2017-2018 годах АСПОС ОКП обеспечила независимый от других источников информации мониторинг более 7500 сопровождаемых КО на высоких орбитах (рис.4). Это в 2,1 раза больше, чем количество объектов, по которым США публикуют орбитальную информацию на сайтах https://www.spacetrack.org/ и https://www.celestrak.com.

Получено более 30 млн измеренных положений КО на фоне звезд. За два года обнаружено более 1600 новых, ранее не наблюдаемых высокоорбитальных объектов. Большинство из этих объектов представляют собой фрагменты, образовавшиеся в результате разрушений. В 2017 году в области ГСО были обнаружены фрагменты, которые образовались в результате нештатных ситуаций с функционирующими космическими аппаратами Telcom-1 (Индонезия), INSAT-3C (Индия) и AMC-9 (США). В 2018 году были зафиксированы два значительных разрушения КО. В обоих случаях разрушились ступени американских ракет-носителей. Одна - в области ГСО, вторая - в области ВЭО.

Продолжена планомерная работа по совершенствованию технологии оперативного обнаружения объектов новых запусков с целью как можно более быстрого определения параметров орбит новых КО и оценки вероятности столкновения новых КО с сопровождаемыми космическими аппаратами.

В целях оценки того, насколько проводимые в ОКП операции соответствуют действующим рекомендациям, стандартам и руководящим принципам, обеспечивается мониторинг объектов, уводимых на орбиту захоронения или орбиту 


\begin{tabular}{|c|c|c|c|}
\hline $\begin{array}{c}\text { Повседневный мониторинг } \\
\text { объектов на высоких } \\
\text { орбитах }\end{array}$ & $\begin{array}{c}\text { Выявление опасных } \\
\text { сближений }\end{array}$ & Контроль запусков & $\begin{array}{l}\text { Обнаружение } \\
\text { разрушений }\end{array}$ \\
\hline $\begin{array}{l}\text { Более } 7500 \text { сопровождаемых } \\
\text { высокоорбитальных космиче- } \\
\text { ских объектов } \\
\text { Получено более } 30 \text { млн } \\
\text { измерений } \\
\text { Более } 1600 \text { ранее не наблюдав- } \\
\text { шихся малоразмерных } \\
\text { объектов обнаружено на } \\
\text { высоких орбитах } \\
\text { Получаемый объем измерений } \\
\text { позволяет обнаруживать } \\
\text { изменения траекторий } \\
\text { движения (маневры) КА на } \\
\text { высокихорбитахи оперативно } \\
\text { оценивать параметры новой } \\
\text { траектории движения (орбиты) }\end{array}$ & $\begin{array}{l}\text { Более } 15000 \text { прохождений } \\
\text { космических объектов, } \\
\text { нарушающих 15-Км зону } \\
\text { безопасности сопровождае- } \\
\text { мых КА } \\
\text { Более } 800 \text { сближений } \\
\text { космических объектов } \\
\text { с сопровождаемыми КА с } \\
\text { минимальным расстоянием } \\
\text { менее 1,5 км } \\
\text { Оповещения о сближениях } \\
\text { Выдаются в ЦуП КК (КС) для } \\
\text { КА, Включенных в перечень } \\
\text { сопровождаемых } \\
\text { На основании информации } \\
\text { АСПОс ОКП проведено } \\
\text { уклонение КА "Канопус-В" } \\
\text { №1 от столкновения с КО, } \\
\text { прекратившим активное } \\
\text { функционирование }\end{array}$ & $\begin{array}{l}\text { Для отечественных запусков } \\
\text { на ГСО, ВЭО и СВО обеспечен } \\
\text { контроль отделения КА } \\
\text { от РБ и увода РБ на орбиту } \\
\text { захоронения } \\
\\
\text { Обеспечено оперативное } \\
\text { обнаружение (через } \\
\text { 5,5-7 ч после запуска) } \\
\text { КО при запусках сарубеж- } \\
\text { ных космодромов на } \\
\text { высокие орбиты }\end{array}$ & $\begin{array}{l}\text { Обнаружены разрушения } \\
\text { космических объектов на } \\
\text { геостационарной орбите } \\
\text { (КА Tеlkот-1, INSAT-3С, } \\
\text { АМС-9, РБ Транстейдж-17, } \\
\text { Бриз-М) }\end{array}$ \\
\hline
\end{tabular}

Рис.7. Результаты применения АСПОС ОКП в 2017-2018 годах

Fig.7. The results of the application of ASPOS OKP in 2017-2018

с сокращенным сроком баллистического существования. Так, например, российскими средствами мониторинга и центрами обработки и анализа информации получены данные о двух связанных с наиболее крупными (с точки зрения количества образовавшихся объектов космического мусора) разрушениями американских ступеней, произошедших и зафиксированных на орбите в 2018 году.

Разрушение ступени Транстейдж 17 произошло в области ГСО 28 февраля 2018 года. В результате разрушения образовалось большое количество фрагмен ${ }^{-}$ тов космического мусора, более 140 из которых были обнаружены средствами АСПОС ОКП и привлекаемыми ОЭС. Данное разрушение привело к увеличению количества потенциально опасных отслеживаемых объектов в области ГСО более чем на 7\%.

Разрушение ступени Центавр произошло в области ВЭО 30 августа 2018 года. Средствами АСПОС ОКП и привлекаемыми ОЭС было обнаружено и взято на сопровождение более 550 фрагментов разрушения. Данное разрушение привело к увеличению количества отслеживаемых потенциально опасных объектов в области ВЭО более чем на $25 \%$.

Более 20\% из сопровождаемых в настоящее время объектов на высоких орбитах являются малоразмерными, либо малозаметными в силу физических свойств материалов, образующих поверхность объектов. Как следствие, для их устойчивого наблюдения необходимо привлечение достаточно мощных оптико-электронных средств с апертурой не менее 70-80 см. Телескопы с наибольшим проницанием - АЗТ-33ВМ и АЗТ-33ИК в Саянской обсерватории Института солнечно-земной физики Сибирского отделения РАН, К-800 и Цейсс-2000 в обсерватории Пик Терскол, ОЭС-65 в составе ЭОП-2 АСПОС ОКП, ОЭС-50 АО "АНЦ" в Чили уже обнаружили значительное количество наиболее слабых объектов в области ГСО. Видимая звездная величина этих объектов - 18,5-19 и слабее. Соответственно, для устойчивого сопровождения таких объектов необходимо либо больше телескопов с апертурой 1 м и более, либо светосильные телескопы класса 0,5-0,6 м и более, установленные в районах с очень хорошим астроклиматом. Кроме того, крупноапертурные телескопы необходимы для получения по космическим объектам различных классов такой некоординатной информации, как кривые блеска в интегральном свете, показатели цвета, спектры.

сША после обнародования российской стороной объективной информации о произошедшем событии в начале октября 2018 года подтвердили факт разрушения, фактическая информация по фрагментам разрушения в настоящее время уточняется.

Фрагменты разрушения ступени Центавр проходят через область размещения всех глобальных спутниковых навигационных систем (ГНСС) - ГЛОНАСС, GPS, Galileo и Beidou. Через 1,5-2 года в результате эволюции орбит фрагменты 
данного разрушения начнут проходить через геостационарную область и будут представлять угрозу для геостационарных КА.

Федеральной космической программой России предусмотрено дальнейшее развитие системы АСПОС ОКП - создание ее третьей очереди.

Конечной целью развития АСПОС ОКП является создание единой национальной системы мониторинга объектов и событий в ОКП и предупреждения о космических угрозах как совокупности взаимоувязанных на единой информационно-логической основе и объединенных на базе единой информационной платформы центров, систем и технических средств различной ведомственной принадлежности, обеспечивающих сбор, обработку и анализ информации о ситуации в ОКП и выработку рекомендаций по парированию угроз в космосе и из космоса для Российской Федерации и ее союзников.

Кроме того, планируется создание открытого информационного сервиса по предоставлению информации мониторинга широкому кругу потребителей, включая зарубежных.

Развитие АСПОС ОКП будет осуществляться по двум основным направлениям. Первое направление связано с совершенствованием сети специализированных инструментов мониторинга (в том числе за счет создания орбитального сегмента, современных радиолокационных станций и станций мониторинга радиолиний КА). При этом предполагается не только модернизация существующих и создание новых инструментов, но и внедрение новых технологий мониторинга, а также расширение номенклатуры первичной измерительной информации мониторинга (цветная фотометрия, спектрометрия, поляриметрия, некоординатная радиолокационная информация, характеристики излучений КА).

Расширение номенклатуры первичной измерительной информации может быть обеспечено привлечением к этой работе организаций РАН, которые могли бы внести серьезный вклад в разработку необходимой аппаратурной части для получения таких измерений, а также в разработку на серьезной научной основе методического и программноалгоритмического аппарата для обработки новых видов измерительной информации и интерпретации получаемых результатов.

Второе направление развития АСПОС ОКП связано с разработкой и внедрением современных методов обработки и анализа информации мониторинга, оценки и прогнозирования обстановки в ОКП, в том числе за счет создания (уточнения) соответствующих моделей космической среды и моделей возмущающих факторов. В данном вопросе профильные институты Госкорпорации "Роскосмос" и РАН обладают необходимым заделом и компетенциями.

Разворачиваемый перспективный комплекс специализированных оптико-электронных средств должен обеспечивать мониторинг всей дуги ГСО, а также возможность получения измерительной информации по большому количеству низкоорбитальных и высокоорбитальных космических объектов. По предварительным планам, КСОЭС будет включать 65 телескопов, 30 из которых будут размещены в Западном полушарии, а 35 - в Восточном (см. рис.8).

С учетом ожидаемого развертывания сверхбольших спутниковых группировок, а также резкого увеличения количества малоразмерных КА на орбитах разных типов, прорабатываются вопросы создания новых или привлечения существующих радиолокаторов, а также размещения оптико-электронных комплексов мониторинга на борту космических аппаратов.

Работы по развитию системы АСПОС ОКП должны быть подкреплены научными исследованиями по следующим направлениям:

- повышение точности и полноты прогнозной информации об опасностях и угрозах, связанных с техногенными космическими объектами, в том числе за счет использования расширенной номенклатуры первичной измерительной информации;

- увязка на основе современных научных подходов требований к информации, используемой для принятия решений по парированию угроз, с требованиями к развитию отдельных средств мониторинга ОКП и системы мониторинга ОКП в целом;

- разработка методов оценивания и прогнозирования параметров движения центра масс космических объектов и параметров движения относительно центра масс для большого многообразия объектов космического мусора с различными орбитальными и физическими характеристиками;

- разработка математических моделей, позволяющих с высокой достоверностью описывать процессы образования и эволюции объектов космического мусора с поперечным размером от нескольких микрометров до нескольких сантиметров, включая оценку вклада взаимных столкновений в "самовоспроизводство" космического мусора;

- внедрение технологий анализа больших массивов данных (Big Data analysis) применительно к задачам выявления закономерностей и тенденций в "поведении космических объектов", в том числе скрытых и неявно выраженных. 


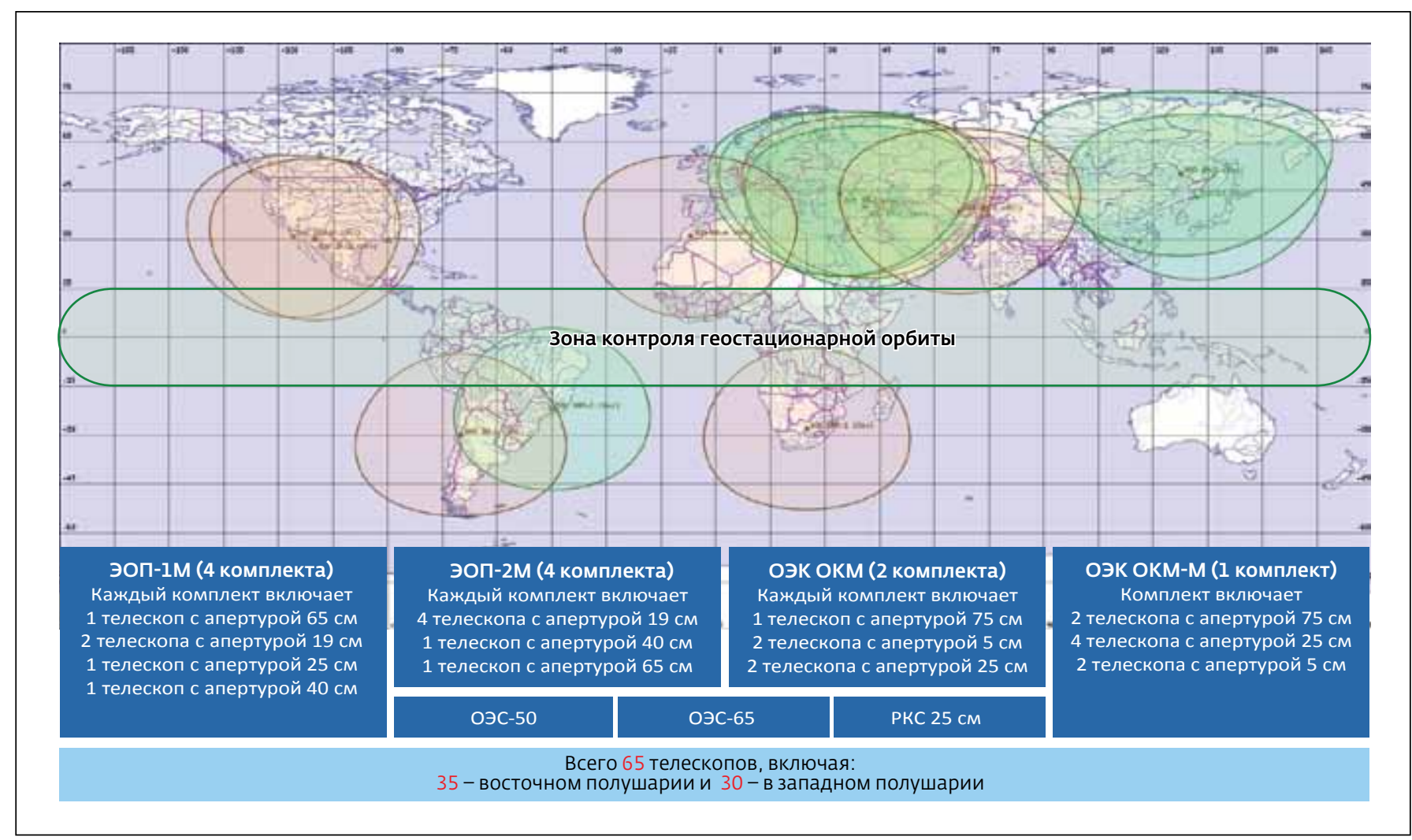

Рис.8. Перспективный комплекс ОЭС системы АСПОС ОКП (зона контроля ГСО по долготе, а также зоны контроля орбит высотой 800 км)

Fig.8. Perspective optoelectronic complex of ASPOS OKP (zone of control of GEO in longitude and zone of control of orbits with a height of $800 \mathrm{~km}$ )

Взаимодействие и сотрудничество Госкорпорации "Роскосмос" и Российской академии наук в сфере мониторинга объектов и событий в околоземном космическом пространстве позволяет скоординировать проводимые исследования и разработки, сосредоточить усилия на решении ключевых проблем развития космической деятельности с точки зрения повышения ее безопасности и долгосрочной устойчивости, а также формирования возможных перспективных схем ее нормативного регулирования на международном уровне.

Учитывая нарастающую динамику вовлечения стран в мировое космическое сообщество, разнообразие форматов и целей участия в космической деятельности, исключительно важным становится ответственное отношение к вопросам "чистоты космического пространства" для обеспечения долгосрочной устойчивости космической деятельности.

Принятие обоснованных решений о парировании угроз, связанных с неизбежным засорением космического пространства, возможно только на основе достоверной и оперативной информации о состоянии вопроса. В связи с этим фундаментальное значение в сфере безопасности космических операций, защиты космической среды может иметь реализация идеи цифрового (оцифрованного) космического пространства, например, в формате информационно-коммуникационной платформы под эгидой Организации Объединенных Наций.

Глобальный информационно-коммуникационный проект с условным названием "Цифровой космос" может стать эффективным механизмом интеграции усилий государств, международных межправительственных организаций, операторов космических аппаратов, профильных национальных и международных неправительственных организаций, который обеспечит формирование и поддержание доступной во всемирном масштабе непрерывно пополняемой базы данных об объектах, явлениях и событиях в космическом пространстве, снимет назревшие проблемы в области сбора, систематизации, предоставления в общее пользование информации о мировой космической деятельности, в том числе получаемой за счет мониторинга объектов и событий в космическом пространстве. 